\title{
Fenómenos Migratorios y Género: Identidades Femeninas "Remodeladas"
}

\section{Migratory Phenomena and Gender: "Re-modeled" Female Identities}

\author{
Lorena Godoy \\ Centro de Estudios de la Mujer
}

\begin{abstract}
Diversos estudios indican que las migraciones pueden ejercer una influencia fundamental en la identidad de las mujeres. Este ensayo se pregunta por los efectos que pueden tener dos procesos migratorios muy diferentes en la identidad de género de las mujeres: exiliadas chilenas en Europa, en las décadas del setenta y ochenta, e inmigrantes peruanas por razones económicas en Santiago de Chile, en la década del noventa. Para responder a esta pregunta, discute desarrollos teóricos provenientes desde la psicología transcultural con estudios de otras disciplinas, para analizar los procesos de aculturación psicológica que experimentan las mujeres migrantes.
\end{abstract}

Palabras Clave: identidad de género, mujeres, migraciones, exilio.

\begin{abstract}
Migrations have important implications for women's identities. From this statement, this essay asks for the consequences of two migratory processes very different in the women's gender identity: the Chilean women in Europe, exiled by the military dictatorship regime, and of Peruvian immigrant women in Santiago, during the nineties. To answer this question, the essay proposes to establish a relation between theoretical developments from transcultural psychology, and other discipline's studies, to analyze psychological acculturation processes of immigrant women.
\end{abstract}

Keywords: gender identity, women, migrations, exile.

\section{El Fenómeno Migratorio Contemporáneo}

En las últimas décadas, los fenómenos migratorios muestran características que los diferencian de los ocurridos en anteriores períodos. Una creciente globalización, pues cada vez más países se ven involucrados en migraciones; una aceleración, que se refleja en el aumento de la cantidad de migrantes; una heterogeneización, ya que muchos países tienen diversos tipos de migración (política, económica, permanente, temporal); y una creciente feminización. Estos rasgos han llevado a Castles y Miller (1998) a denominar el momento actual como la "era de la migración".

La estrecha relación entre el proceso de globalización y las migraciones, explica muchas de estas características. El desarrollo tecnológico acerca las posibilidades de emigrar al reducir los costos de traslado y hacer más visibles los posibles benefi-

Lorena Godoy Catalán, Investigadora del Centro de Estudios de la Mujer, Chile.

La correspondencia relativa al artículo debe enviarse a la autora a: Centro de Estudios de la Mujer, Purísima 353, Santiago de Chile. E-mail: 1godoyc@puc.cl o 1godoy@cem.cl cios; y junto con ello, las migraciones constituyen canales que acercan a sociedades muy diferentes. Pero al mismo tiempo, la distribución de migrantes, que se concentran en regiones más desarrolladas ${ }^{1}$, refleja y acentúa las marcadas desigualdades del orden económico a nivel internacional.

Una de las características de las migraciones contemporáneas que ha cobrado especial relevancia ha sido el constante crecimiento de la participación de mujeres. Para el año 2000 el 48\% de los 175 millones de migrantes a nivel mundial eran mujeres (United Nations, 2002) y, en América Latina, el año 2002 ellas representaban el $50.5 \%$ de los migrantes (Ramírez, García \& Míguez, 2005).

Aunque esta tendencia a la feminización se advierte desde los años sesenta, en los últimos años se aprecia un cambio en el patrón tradicional de la migración femenina, de uno "asociativo" (migración vinculada a un migrante titular masculino) a uno "autónomo”, pues cada vez más mujeres migran solas (Ramírez, García \& Míguez, 2005).

\footnotetext{
I Entre el año 1995 y el 2000, las regiones más desarrolladas recibieron cerca de 12 millones de inmigrantes desde las menos desarrolladas (United Nations, 2002).
} 
En Chile se advierte un vigoroso aumento del número de inmigrantes especialmente desde la segunda mitad de los años noventa: en el año 2002 el número inmigrantes se elevó a 185 mil, el más alto desde 1952.

Respecto de la composición por sexo, Martínez (2003) indica un ligero predominio de mujeres en el total de inmigrantes, siendo uno de los hechos más llamativos el fuerte predominio de mujeres peruanas. Aunque la migración intrarregional presenta un porcentaje bastante parejo entre hombres y mujeres, el caso peruano constituye una excepción pues ellas superan a los hombres, lo que coincide con la feminización de la migración peruana que se dirige a distintos destinos (Stefoni, 2003).

\section{La Feminización de las Migraciones}

Detrás de la feminización de las migraciones hay una compleja red de acontecimientos económicos, políticos y culturales. Por una parte, está imbricada con dinámicas constitutivas de la globalización económica, contexto en el que surgen circuitos globales alternativos de supervivencia, a los que Sassen (2003) denomina "contra geografías de la globalización”. Estos circuitos incluyen las migraciones transfronterizas, cuyo destino es el mercado laboral externo y el tráfico ilegal de personas destinadas al comercio sexual, que surgen como alternativas para conseguir recursos para la subsistencia y como fuente de remesas para los países emisores. Entre los actores clave que emergen en estos circuitos se encuentran las mujeres, grupo mayoritario en la industria del sexo y crecientemente en la migración por motivos económicos.

Sin embargo, un análisis centrado sólo en lo económico invisibiliza otras dimensiones que también inciden en esta creciente feminización. Una de ellas son las relaciones de género, las que en el caso de las migraciones latinoamericanas, a menudo constituyen "una forma de exclusión social en el contexto de origen" que motiva a las mujeres a migrar (Wagner, 2004, p. 4).

Así, el aumento de mujeres en las migraciones ha puesto en evidencia la gravitación que puede tener el género en los fenómenos migratorios, en tanto dimensión constituyente de la identidad y elemento que históricamente ha tenido un poder ordenador y jerarquizador de las relaciones sociales. Diversos estudios han señalado que los estereotipos y las desigualdades de género permiten explicar la decisión de migrar, las redes empleadas para hacer- lo, la inserción social y laboral en el país de acogida, así como los significados que las personas atribuyan a esta experiencia. A su vez, las migraciones influyen en las relaciones de género, ya sea afianzando las desigualdades y roles tradicionales, o bien desafiándolos (BRIDGE, 2005; Rebolledo, 2005; Vásquez \& Araujo, 1990).

Desde esta perspectiva, la categoría de género evidencia cómo ciertas características del propio migrante, la identificación que una persona hace de sí misma como hombre o mujer (identidad de género), la forma como dicha autopercepción organiza y da sentido a sus acciones en el mundo, así como la posición que hombres y mujeres ocupan en las estructuras sociales, son elementos necesarios de considerar para comprender los fenómenos migratorios y sus efectos en la vida de las personas.

A partir de lo señalado, la pregunta en torno a la que se estructura este ensayo se refiere a los posibles efectos de procesos migratorios en las identidades de género de mujeres migrantes.

Algo que se constata de la revisión de diversas investigaciones, es que las migraciones pueden ejercer una influencia fundamental en la identidad de las mujeres. Es decir, el contacto directo y continuo de grupos culturales diferentes, con los consecuentes cambios en los patrones culturales originales de uno u otro - proceso de aculturación (Berry, 1997)- en el caso de las inmigrantes, afecta su forma de verse como mujeres (Vásquez \& Araujo, 1990).

En ocasiones, las mujeres pueden experimentar una suerte de "descubrimiento" de la propia identidad, a partir del cuestionamiento de estereotipos y roles femeninos propiciado por el contacto con otros grupos culturales, lo que es vivido como mayor libertad y autonomía personal. En otras ocasiones, la cultura de acogida refuerza estereotipos de género, por ejemplo, ofreciendo una inserción laboral fuertemente segregada en base a roles de género, estrechando las posibilidades de inserción social y desarrollo personal.

Aunque lo señalado no desconoce los posibles efectos que las migraciones también pueden tener en las identidades de género de los hombres, para los propósitos de este ensayo se ha estimado más adecuado discutir la experiencia de las mujeres por los significativos cambios que muestra su participación en los procesos migratorios a nivel mundial. Pero también debido a la mayor evidencia que se dispone, ya que en el ámbito de las investigaciones sobre migraciones, la introducción de una perspectiva de género aún se remite, predominantemente, al estudio de mujeres. 
A partir de lo señalado, este ensayo pone en relación ciertos planteamientos teóricos provenientes de estudios de la psicología transcultural sobre fenómenos migratorios, con estudios empíricos desde la psicología y la sociología, a fin de discutir la influencia que pueden tener las migraciones en la identidad de género de las mujeres. Dicha discusión se centrará en dos tipos de migraciones: el exilio de chilenas en Europa durante la década del setenta, y la migración económica de peruanas en Santiago durante los noventa. Se trata entonces de un ensayo de carácter teórico, basado en fuentes secundarias.

\section{Perspectivas Conceptuales}

\section{Las Migraciones Como Desafios Identitarios}

Desde la psicología transcultural, se ha señalado que el proceso de aculturación es tanto un fenómeno colectivo como individual que implica cambios en la cultura de un grupo y en la psicología de un individuo (aculturación psicológica) (Graves, 1967 citado en Berry, 1997). Entre los cambios a nivel individual, se encuentran los que ocurren en la identidad de las personas, es decir, en el sentido de sí mismo que se forma en un proceso en que confluyen tanto mecanismos psicológicos (cognitivos, emocionales, motivacionales) como los contextos socioculturales en los que los individuos ocupan distintas posiciones en las estructuras sociales (Serrano, $\mathrm{s} / \mathrm{f}$ ).

Desde una perspectiva psicoanalítica, Grinberg y Grinberg (1996) señalan que las migraciones constituyen cambios en la vida de las personas que pueden ser de tal magnitud que pongan en evidencia e incluso en riesgo, su propia identidad ("rupturas identitarias").

Vásquez y Araujo (1990) indican que la "situación existencial límite" que puede llegar a constituir el exilio, plantea "de manera aguda y desgarradora la problemática de nuestra identidad. Porque cuando todo se torna incierto y un viejo mundo se desmorona, la pregunta ‘¿quiénes somos?' se plantea inexorablemente" (p. 146).

En la construcción de las identidades personales, el género constituye una dimensión fundamental "que interviene en la representación, interpretación y evaluación de los acontecimientos y del propio auto concepto, así como en la regulación, activación y direccionalidad de las acciones" (Barberá, 1998, p. 21). El sentimiento de pertenencia a uno u otro género (identidad de género), incide en la forma como hombres y mujeres se ven a sí mismos y al mundo, y cómo actúan en él.

Vásquez y Araujo (1990) indican que en medio del "despojo esencial simbolizado por el exilio", lo que permanece por encima de todo es precisamente la imagen que las mujeres tienen de sí mismas, que "transciende todo tipo de militantismo, porque aún las más militantes y las más ortodoxas, conservan en ellas el modelo transmitido por las abuelas, las madres y las tías" (p. 153). Así, las mujeres se relacionan con el mundo a partir de los estereotipos y códigos de comportamiento de género.

El modelo de Berry (1997) para la investigación sobre aculturación, señala la presencia de factores previos a la migración que median o moderan los efectos de ella en los procesos de aculturación psicológica. Grinberg y Grinberg (1996), por su parte, indican que factores personales previos a la migración pueden anticipar efectos positivos o negativos en los individuos migrantes del contacto entre distintos grupos culturales.

Lo que aquí interesa destacar es que la autopercepción en tanto mujeres u hombres de los migrantes, es decir, la identidad de género, puede constituir un factor previo a la migración fundamental para entender cómo es experimentada. Es lo que indican Vásquez y Araujo (1990) para el caso de los exiliados latinoamericanos en Europa al sostener que:

El modo como estos desterrados vivirán su exilio (...) no se puede explicar solamente por las causas que lo provocaron, sino que es tributario de la imagen que tenían de sí mismos antes de partir, así como de sus representaciones y estereotipos sobre el viejo continente. (p. 14)

\section{Experiencias Migratorias de Mujeres: Compromiso Político y Estrategias de Subsistencia}

Los procesos migratorios aquí analizados son claramente diferentes. Mientras las exiliadas chilenas lo hacen expulsadas por razones políticas, las mujeres peruanas emigran como parte de una estrategia de subsistencia familiar; mientras las primeras tienen la imposibilidad del retorno, en el caso de las segundas éste depende de ellas. Unas siguen un patrón asociativo de migración, en tanto otras lo hacen siguiendo un patrón autónomo. Sin embargo, ambos procesos involucran a mujeres, que salen o que llegan a Chile.

Los estudios existentes sobre los efectos de la migración en las identidades de género de mujeres 
difieren notoriamente en un caso y otro. Existe mayor reflexión sobre esta temática en el caso de las exiliadas chilenas, en tanto sobre inmigrantes peruanas los estudios consultados se centran más en el análisis de sus aspectos sociodemográficos, así como en las características de su inserción laboral y social en Chile.

Entre los estudios que se refieren al exilio, se consultó el de las autoras Ana Vásquez (psicóloga) y Ana María Araujo (socióloga) (1990) sobre mujeres latinoamericanas exiliadas en países europeos francófonos. En rigor, este trabajo no constituye una investigación sino un análisis de la propia práctica clínica de las autoras, los testimonios no son de participantes de un estudio sino de sus pacientes; sin embargo también se incluye la reflexión de las autoras sobre su propia condición de exiliadas. También se revisó la investigación realizada por la psicóloga Inger Agger (1993) sobre exiladas latinoamericanas y del Medio Oriente en Dinamarca. Este estudio utiliza el testimonio como método de investigación, lo que como indica Agger "implica que el proceso de investigación y el proceso terapéutico no pueden separarse totalmente" (p. 15). Se consultaron además investigaciones realizadas por la antropóloga Loreto Rebolledo $(2001,2005)$ que iluminan otros aspectos del exilio.

En el caso de la inmigración peruana, además de los estudios que caracterizan socio-demográficamente a esta población, se tuvo acceso a entrevistas realizadas en el estudio de Fuentes y Reyes (2003) sobre peruanas en Chile, que si bien obedecen a un propósito diferente, permiten otra aproximación a la experiencia de las inmigrantes peruanas. Se revisaron además algunos trabajos referidos a la experiencia de mujeres inmigrantes de otros países andinos.

\section{Las Exiliadas Chilenas en Países Europeos}

Características generales del exilio. Se estima que el exilio chileno involucró alrededor de $260 \mathrm{mil}$ personas. La gran mayoría de los titulares del exilio fueron hombres jóvenes con responsabilidades familiares. En general, ellos salieron con sus familias, lo que caracteriza al chileno como un exilio familiar. Se trató además de un destierro amplio en términos políticos y sociales, pues incluyó a personas con y sin militancia, y a profesionales, técnicos, obreros, campesinos y dueñas de casa (Rebolledo, 2005).

El duelo que caracteriza las primeras etapas de las migraciones, que alude al desafio y al dolor (Grinberg \& Grinberg, 1996), en el caso de los exiliados comprende tanto la pérdida de un proyecto personal como un proyecto social y político, el fin de un modus vivendi (Vásquez \& Araujo, 1990).
Un sentimiento de culpa adquiere especial relevancia, pues el destierro no es sólo una forma de castigo, sino también una manera de librarse de la muerte que alcanzó a tantos otros compañeros.

El duelo y la culpa conviven con un fuerte desamparo, pues las personas difícilmente encuentran "su lugar" dentro de la nueva comunidad. Necesitan imperiosamente una persona o un grupo que asuma funciones de "maternaje" y "continencia", una especie de "padrinos" o padres sustitutos que les permitan recuperar el ligamen con la realidad (Grinberg \& Grinberg, 1996).

En el caso del exilio chileno, este "maternaje" es muy marcado. En las primeras etapas, los exiliados muestran un rechazo por el país de acogida y se concentran en ciertos barrios lo que facilita la creación de comunidades e instituciones que refuerzan el compromiso político. Todo esto auspició una conducta de ghetto (Rebolledo, 2005), en que la comunidad pasó a ser la "familia ampliada", ejerciendo funciones de protección, pero al mismo tiempo de control e inclusive culpabilización (Vásquez \& Araujo, 1990).

Los exiliados idealizan y magnifican el país de origen, constituyendo éste el principal mecanismo de defensa. La instalación en el nuevo país se piensa siempre provisoria. Se vive para retornar. Todo esto constituye "una especie de freno que atrasa el aterrizaje psicológico" de los exiliados (Vásquez \& Araujo, 1990, p. 47).

Con el transcurso del tiempo, ellos incorporan lenta y progresivamente elementos de la nueva cultura y comienzan a percibir el control que ejerce la propia comunidad, de la cual comienzan paulatinamente a alejarse. El mayor contacto con la sociedad de acogida se ve facilitado por la propia idea de latinidad de los europeos (estereotipos positivos), y la existencia de una institucionalidad que protegía a los refugiados.

Caracterización de las mujeres exiliadas. Jóvenes, dueñas de casa, profesionales y obreras, militantes o simpatizantes, son algunos rasgos que las caracterizan. En general, su partida estuvo vinculada a sus parejas, lo que configura un patrón predominantemente asociativo de migración. Y en la mayoría de los casos también, fueron ellas quienes se hicieron cargo de las tareas reproductivas, del cuidado, educación y salud de los hijos. Aunque esto no constituyó una novedad, sí lo fue el contexto en el cual lo hicieron. Sociedades más orientadas a reconocer la igualdad de derechos de hombres y mujeres que proveyeron a los refugiados de las condiciones materiales para la subsistencia. De algún 
modo, ello liberó a los hombres de sus responsabilidades tradicionales de provisión familiar y les permitió dedicarse predominantemente a la militancia política. El estar en manos de las mujeres la vinculación con escuelas, hospitales, supermercados, las obligó a aprender mucho más rápido que ellos el idioma, las normas culturales y la institucionalidad del nuevo país.

Vásquez y Araujo (1990) señalan que el destierro se convirtió para muchas en una experiencia de cuestionamiento de sus identidades, generando quiebres que se transformaron en verdaderos desafíos y oportunidades para construir identidades femeninas más autónomas. Rebolledo (2005) indica que este "viaje interior, tributario absoluto (...) del desplazamiento geográfico, fue el que permitió modificar las identidades de las exiliadas chilenas" (p. 155). Esto explica que junto con la presencia de una memoria sobre el exilio compartida por hombres y mujeres caracterizada por la idea de desarraigo y tiempo suspendido, existan memorias más específicas, ancladas en las mujeres, que hablan del exilio como un proceso de individuación, de mayor capacidad reflexiva, de mayores posibilidades de ser ellas mismas (Rebolledo, 2001). Una exiliada señala al respecto: "No puedo decir cuando, cómo o dónde, pero se que hubo un cambio esencial en mí. Me atrevería a decir que mi identidad de mujer adulta se construyó en el exilio" (Vásquez \& Araujo, 1990, p. 163)

Por supuesto que estas consecuencias positivas no ocurrieron sin conflicto, y Rebolledo (2005) sostiene que el proceso descrito refleja más la realidad de exiliadas de clase media y profesionales que la de sectores populares. Pero además, el exilio trajo una serie de consecuencias dolorosas. Agger (1993) indica que para algunas el conflicto de identidad se inició antes de la partida. Para las mujeres con militancia política, ello significó un desplazamiento al espacio público y un desafío al poder masculino. Fue esta transgresión de los límites femeninos -y no sólo el ser portadoras de un proyecto político de izquierda- lo que fue castigado con la cárcel, la tortura y el destierro, castigo que en el caso de las mujeres tomó la forma predominante de violencia sexual. Ello produjo consecuencias traumáticas que incidieron en la forma de experimentar el exilio, predominantemente como un castigo, y en las relaciones con parejas e hijos. Una exiliada lo expresa así:

Algunas veces pienso que no debería vivir. Yo no pertenezco ni a Dinamarca ni a mi país, y ¿dónde estar? Tengo el sentimiento de que no soy nadie. (...). Me siento a menudo culpable: debie- ra haberme quedado, como me dijo mi padre. Racionalmente yo puedo ver que es la culpa de los que tienen el poder, pero cuando lloro y me pongo triste, siento que debería haberme quedado. (...) Ser exiliada es para mí un castigo. No puedo verlo de otro modo. (Agger, 1993, p. 156)

Por otra parte, para muchas exiliadas el fuerte control y culpabilización que ejerció la comunidad propia, pueden haber dificultado el experimentar sin culpas las posibilidades de mayor autonomía que les abría el país de acogida. De hecho, algunas mujeres, mantuvieron una actitud crítica hacia los valores más "liberales" de los países de acogida. Vásquez y Araujo (1990) indican que en un primer momento las mujeres tendieron a refugiarse en un "discurso tradicional y conservador posicionándose como las garantes de la familia y el hogar" (p. 149). Aunque en un segundo momento muchas expresan una mayor apertura a la sociedad de acogida, produciéndose una "especie de deslumbramiento" por las posibilidades que les ofrecía, otras mantuvieron la actitud crítica ahora no sólo hacia el país de acogida, sino hacia aquellas compatriotas que hacían suyas estas nuevas oportunidades.

Surgen además modelos femeninos más consecuentes con los estereotipos de género. Rebolledo (2005) menciona el caso de las mujeres viudas:

Prisioneras del partido y de sus íconos, madre y padre a la vez de sus hijos, cargados con el peso de la orfandad real del padre, y el peso simbólico de ser hijos de un mártir o de un héroe, estas mujeres vieron coartadas sus posibilidades de reconstruir parejas y rearmar familia. (p. 157-158)

\section{Mujeres Peruanas en Santiago de Chile en los Noventa}

Caracterización general de la migración peruana actual. De acuerdo a datos del censo de 2002, la migración peruana a Chile representa el $21 \%$ de los extranjeros residentes en Chile y ha experimentado un marcado crecimiento a partir de la segunda mitad de los años noventa.

En su mayoría se trata de una migración económica, lo cual se evidencia en sus altas tasas de participación laboral: en el caso de los hombres ella supera el $85 \%$ y es cercana al $80 \%$ para las mujeres.

Se trata mayoritariamente de personas jóvenes, cerca del $50 \%$ de los hombres y mujeres se concentran entre los 15 y 44 años de edad (Martínez, 2003); con diversos niveles educacionales, pero que en general superan los de población activa chilena; que 
provienen de diferentes sectores sociales y mayoritariamente de ciudades al norte del Perú (Chimbote o Trujillo) muy golpeadas por la crisis económica y política de los noventa.

Entre estas zonas y Chile se forman verdaderas cadenas migratorias, "conjuntos de vínculos interpersonales que conectan a migrantes, migrantes antiguos y no migrantes en su área de origen y de destino a través de lazos de parentesco, amistad y comunidad de origen compartida" (Massey, 1998 citado en Stefoni, 2003, p. 34). La presencia de estas redes es crucial para entender los flujos migratorios, ya que aumentan las posibilidades de migrar, reducen los costos de traslado, mitigan los riesgos y ayudan a la inserción laboral en la sociedad de acogida.

Así, junto con la cercanía geográfica, el compartir el mismo idioma, el bajo costo del traslado, la no exigencia de visa y la transmisión de una imagen de Chile como "un país de grandes posibilidades, modelo de desarrollo liberal exitoso", la presencia de estas cadenas explica el crecimiento que ha experimentado esta migración. Ellas "jalan" a nuevos migrantes, y cual "maternaje" actúan como redes de acogida claves para la instalación e inserción laboral y social en el nuevo país.

La inserción laboral de los inmigrantes peruanos es fuertemente segregada. La generalidad de los hombres se desempeña en la construcción y el comercio minorista, y las mujeres en el servicio doméstico, lo cual limita las posibilidades de desarrollo laboral y de inserción social. Pero además constituye una manifestación de estereotipos predominantemente negativos de los chilenos hacia la población peruana. El crecimiento acelerado que experimentó a mediados de los noventa esta migración hizo creer a la opinión pública que los peruanos venían en oleadas fuera de control ${ }^{3}$. Ello, unido a históricas disputas y prejuicios raciales y clasistas, generan imágenes de los peruanos como una amenaza para las fuentes laborales y como personas pobres que representan "cargas" para la sociedad. Esto va más allá de la evidencia que indica que en su mayoría, las/os peruanas/os constituyen una "mano de obra complementaria" que satisface la demanda de trabajo en ocupaciones de baja tecnología y poco atractivas para los nacionales (Stefoni, 2003).

2 Es lo que señala un dirigente peruano entrevistado en el estudio de Fuentes y Reyes (2003).

3 Lo cual contrasta con el reducido porcentaje que representa el número total de inmigrantes sobre la población nacional: en 2002 alcanzaba apenas el 1.22\% (Martínez, 2003).
Caracterización de las inmigrantes peruanas. Para el año 2002, el 60\% de los residentes peruanos en Chile eran mujeres, y en términos absolutos su número había crecido entre 1992 y 2002 de 7649 a 39084 personas.

Se trata en su mayoría de mujeres jóvenes, casi un $20 \%$ cuenta con formación profesional y con experiencia laboral previa a la migración. Más del $85 \%$ es madre y la gran mayoría deja a sus hijos en el Perú al cuidado de otra mujer (madres, hermanas, tías) para migrar solas como parte de una estrategia de subsistencia familiar (Martínez, 2003).

Para el año 2002, un 71\% se desempeñaba en el servicio doméstico (nanas), lo que representa una intensificación de la segregación laboral pues diez años antes un $14.3 \%$ se desempeñaba en este empleo (Martínez, 2003).

Esta fuerte segregación laboral tiene como consecuencia el establecimiento de una suerte de "cadena transnacional de cuidadoras", en que el trabajo de las mujeres inmigrantes hace posible el trabajo remunerado de mujeres en países desarrollados, y a su vez el trabajo de la mujer migrante sólo es posible por el apoyo de otras mujeres, madres, hermanas, que cuidan de los hijos que ha debido dejar (Stefoni, 2003).

Ello refleja y reproduce la división sexual del trabajo a nivel internacional, y refleja y refuerza al mismo tiempo estereotipos de género que asignan a las mujeres atributos vinculados con el cuidado y bienestar de otros, que suponen afecto, sensibilidad interpersonal, calidez y amabilidad.

Para el caso de las inmigrantes peruanas en Chile, entrevistas realizadas a empleadores de "nanas peruanas" muestran que ellas son vistas como mujeres que provienen de un contexto social en que el machismo "está más metido" que en Chile y por lo tanto "son más denigradas que las chilenas". Ello se traduce en mayor humildad y docilidad, lo que representaría "una ventaja" pues las hace "más domables, más fáciles de manejar" (Stefoni, 2003, pp. 96-97). Así, los prejuicios raciales y clasistas hacia la migración peruana, se potencian con este prejuicio de género.

\section{Identidades de Género "Remodeladas"}

De lo señalado se desprende que los efectos de las migraciones en las identidades de género son complejos y suelen ser paradojales. En los casos analizados, la incertidumbre y la "situación existencial límite" que puede representar la migración, conduce 
a procesos de aculturación psicológica que dan origen a particulares mixturas que cada individuo hace de elementos antiguos y nuevos que pasan a conformar su identidad. Esta mixtura, al mismo tiempo que les permite reconstruir su identidad (en el sentido de seguir siendo los mismos), les posibilita incorporar elementos de la nueva cultura.

Grinberg y Grinberg (1996) denominan esta mixtura como un "sentimiento de identidad remodelado" que conduce a la emergencia de una persona que al mismo tiempo que es diferente, sigue siendo quien era antes de emigrar.

Siguiendo este planteamiento, a través del análisis de algunas dimensiones de la identidad de género de las mujeres, es posible apreciar la convivencia de elementos de cambio y de continuidad en estas identidades, los que al mismo tiempo que reflejan la mantención de estereotipos de género, expresan las posibilidades de mayor individuación que la experiencia migratoria les puede ofrecer.

Las dimensiones de la identidad femenina analizadas constituyen áreas de significación o puntos de referencia relevantes en la vida de las mujeres, que tienen que ver principalmente con la sexualidad y la reproducción (Agger, 1993; Vargas-Thils, 2002). Sin embargo, se ha incluido también la inserción laboral por la gravitación que tiene en la vida de muchas de las mujeres exiliadas y migrantes, y en su auto percepción como mujeres.

Las relaciones de pareja. En el caso del exilio chileno en Europa, si bien la presencia de redes políticas, de una institucionalidad y la misma idea de latinidad de los europeos propició la acogida de refugiados políticos, el destierro significó una pérdida de la red social (amigos, familia, trabajo). Ello convirtió a la pareja-especialmente en las primeras etapas del exilio- en el principal referente y soporte para enfrentar la nueva vida. Aunque en algunos países la creación de una "comunidad de acogida" morigeró esta situación, ello no evitó crisis de pareja. A esto también contribuyeron las oportunidades de mayor realización personal que estas sociedades de acogida brindaban a las mujeres, las que si bien en ocasiones generaron reacciones masculinas que incluyeron la violencia hacia mujeres y niños (Agger, 1993), también condujeron a procesos de cuestionamiento de las identidades femeninas, vinculadas fundamentalmente a la reproducción y cuidado de otros. A este cuestionamiento contribuyó también el sentirse como sujetos en tránsito (Rebolledo, 2005), y la autonomía económica lograda gracias al ejercicio de un trabajo productivo y/o ayuda estatal (la cual era entregada a cada miembro de la familia y no centralizada en el jefe de familia), todo lo cual condujo a muchas mujeres a separarse. Estas rupturas de pareja, dieron paso al establecimiento de nuevas relaciones de pareja de mayor igualdad y reciprocidad, y a la reconfiguración familiar bajo un principio generalmente matricéntrico (Rebolledo, 2005). En otros casos, sin embargo, las experiencias de encarcelamiento, tortura, desaparición y muerte de parejas y familiares, hicieron muy difícil para las exiliadas restablecer una relación amorosa y rearmar familias (Agger, 1993).

A diferencia del exilio chileno, la inmigración actual de mujeres peruanas sigue un patrón marcadamente autónomo. Se trata en su gran mayoría de mujeres que llegan al país solas y que son acogidas fundamentalmente por redes formadas por lazos de parentesco y amistad. Aunque en general esta migración obedece a una estrategia de subsistencia, ellas señalan otras importantes razones: la violencia intrafamiliar, la opresión al interior de las familias y la sobrecarga de trabajo. Estas razones, "actúan como aliciente para que muchas mujeres vean en la migración una liberación de los abusos cometidos contra ellas" (Stefoni, 2003, p. 78), lo que la convierte también en una oportunidad para salir de situaciones de maltrato y abuso y establecer relaciones de género en contextos de mayor autonomía y menor control familiar.

Ello, por supuesto, no ocurre sin dolor y sufrimiento, pues en la mayor parte de los casos se trata de mujeres que son madres y que han debido dejar a sus hijos al cuidado de otras mujeres. Y para la gran mayoría de ellas reunir los recursos suficientes para traer a sus familias o para retornar, es algo difícil de lograr.

La maternidad. Vásquez y Araujo (1990) señalan que una expresión de las transformaciones en las identidades de género de las exiliadas latinoamericanas es que ellas asumen la maternidad más como una opción que como un destino inevitable, cuestión que habría facilitado la vivencia de una maternidad menos dependiente.

No obstante, la maternidad generó para muchas exiliadas sentimientos más controversiales. La persecución política y el exilio pusieron en riesgo también a los hijos y en algunos casos ellos fueron dejados en Chile al cuidado de abuelos u otros familiares. Estas situaciones son vividas por muchas mujeres con sentimientos de culpa que afectan seriamente el tipo de vínculo que establecen con sus hijos (Agger, 1993). 
Entre las inmigrantes peruanas, algunas autoras han señalado que la decisión de migrar tiende a hacerse desde "la lógica sacrificial familiar" (Araujo, Legua \& Ossandón, 2002). Ello porque se trata en su mayoría de madres que migran buscando alternativas para la subsistencia familiar. Junto con el envío de dinero a sus familias, en la práctica "ellas siguen tomando decisiones y resolviendo los problemas familiares a la distancia. No es extraño por ejemplo que diriman conflictos entre los/as hijos/as o decidan acerca de los permisos de salida de éstos" (Araujo, Legua \& Ossandón, 2002, p. 49). Esta "maternidad a la distancia", a juicio de Araujo, Legua y Ossandón (2002) puede provocar trastornos de tipo depresivo, malestares emocionales y en algunos casos es causal de retornos, todo lo cual dificultaría que las mujeres visualicen nuevos horizontes de desarrollo más personal.

Sin embargo, como lo indican las escasas investigaciones existentes, a pesar del sufrimiento que provoca la lejanía de los hijos, el contar con recursos propios, la posibilidad de formar nuevas relaciones de pareja, acceder a nuevos referentes colectivos (no familiares), sí pueden ofrecer horizontes de mayor autonomía e individualización a las mujeres inmigrantes. Cuestión que es especialmente evidente cuando además de las razones económicas, las mujeres aluden a razones de género para migrarrelaciones de maltrato y violencia. Córdova $(\mathrm{s} / \mathrm{f})$, por ejemplo, señala al respecto que algunas mujeres peruanas en Chile se autoperciben como más libres y emancipadas.

La relación con la familia de origen. La separación con la familia de origen puede producir un fuerte sentimiento de desamparo, que se agudiza en la medida que las mujeres se encuentran aisladas en medio de un mundo desconocido. En el caso de las exiliadas, este sentimiento, especialmente agudo en las primeras etapas del exilio, con el tiempo es experimentado también como apertura a otras formas de ser, de hacer familia y de mayor libertad. Sin perder los vínculos afectivos, la distancia disminuye las posibilidades de control social directo que las familias de origen ejercen sobre sus miembros en tanto "guardianas de la tradición" (Rebolledo, 2005).

En otras ocasiones, la relación con la familia de origen está teñida por un sentimiento de culpa. Es lo que señalan algunas exiliadas cuyos padres criticaron su decisión de refugiarse y de no retornar. En estos casos, junto con el apoyo, las mujeres sienten el cuestionamiento y reproche de sus familias, lo que afecta las relaciones con padres e incluso con sus hijos cuando se han quedado al cuidado de ellos (Agger, 1993).

Entre las inmigrantes peruanas, las familias de origen suelen ser un soporte fundamental en la decisión de migrar: son abuelas y hermanas quienes muchas veces se quedan a cargo del cuidado de los hijos. Es decir, familia de origen y familia propia constituyen una unidad que se ha hecho parte de la decisión de migrar, sufre la separación y al mismo tiempo recibe sus beneficios (remesas). El hecho de que estas "familias transnacionales" sean en la mayor parte de los casos dirigidas por mujeres sin duda refleja el modo en que el trabajo de las mujeres de países menos desarrollados posibilita el trabajo remunerado de mujeres en países desarrollados. Pero también ello otorga a las mujeres mayores niveles de autonomía respecto de los hombres en cuanto a la provisión familiar, a la generación y control de recursos. Y es razonable pensar -atendiendo a las múltiples investigaciones que así lo indican- que esta mayor autonomía económica de las mujeres afecta las jerarquías de género al interior de las familias, incrementando su capacidad de decisión.

Trabajo e identidad de género. El ejercicio de una actividad remunerada por un número creciente de mujeres en diferentes países del mundo, y la autonomía económica que hace posible, están estrechamente vinculadas con los cambios en las identidades de género de mujeres en las últimas décadas. $Y$ es que el ejercicio de una actividad remunerada no remite sólo a la subsistencia. Tiene una alta legitimidad y valoración social para las mujeres, ligada a la capacidad de gestión, la función proveedora, el pragmatismo para resolver dificultades y una mayor injerencia y control de los ingresos familiares (Sharim, 2005).

En el caso de las mujeres analizadas, un alto porcentaje ejerce una actividad remunerada. Aún cuando el exilio no "inauguró" el ingreso al mercado laboral de las mujeres (habían algunas que trabajaban remuneradamente antes del exilio), sí masificó esta experiencia. Y en cuanto a la migración peruana, la gran mayoría ha ejercido una actividad remunerada antes de salir de Perú, por cierto, en ocupaciones más calificadas y diversificadas de las que les ofrece Chile.

Para las exiliadas las oportunidades laborales abrieron posibilidades de realización personal y la autonomía económica constituyó una base para la toma de decisiones sobre sus proyectos de pareja y familia; en tanto en el caso de las mujeres peruanas inmigrantes, la inserción laboral -uno de los moti- 
vos principales para migrar- es fuertemente segregada, precisamente por razones de género. Considerando sus niveles educacionales, la inserción laboral predominantemente en el servicio doméstico supone una pérdida de status laboral y social y una subutilización de sus capacidades laborales.

El servicio doméstico es un trabajo que se caracteriza por las bajas remuneraciones y el bajo prestigio social. Las condiciones en las que se realiza generan aislamiento social, lo que se presta a situaciones de abuso (extensión de horarios, poco descanso e intimidad) y ofrece pocas posibilidades de demandar derechos laborales. Una mujer peruana entrevistada en el estudio de Fuentes y Reyes (2003) señala al respecto:

La gente que viene acá por lo general no ha trabajado en esto (...) venirse a encerrar en una casa es tan difícil, es tan difícil (...) y eso a veces la familia chilena no lo entiende. Cuando una quiere salir dicen: "pero por qué usted quiere salir, para qué va a salir, a qué hora va a venir". Una tiene una vida propia (...) déjeme hacer vida, necesito $(. .$.$) por eso es que el estrés es tan alto,$ y por eso el día que salen, salen a bailar, porque es un desasosiego, es una sensación de libertad. (p. 38)

No obstante $-\mathrm{y}$ de manera paradojal- este tipo de ocupación en Chile está más regulada que en otros países, lo que facilita el trámite de solicitud de visa de residencia. El hecho que la legislación obligue a los empleadores de trabajadoras de casa particular a realizar un contrato, permite que más mujeres que hombres tramiten con éxito sus visas. Los empleos ocupados por los hombres, en cambio, tienen menos posibilidades de estar bajo un contrato formal de trabajo y son más inestables.

Con todos los problemas del trabajo doméstico, esta inserción laboral ha permitido a las mujeres generar recursos para el mantenimiento de sus familias, asumiendo un rol de proveedoras del hogar que contribuye a modificar las relaciones de jerarquía entre los géneros al interior de la familia, les otorga más respeto y las dota de mayor confianza y autonomía (Stefoni, 2003, p. 79). Muchas mujeres ven este trabajo como una ocupación "de entrada" al mercado, que les permita instalarse, establecer contactos, idealmente tomar algún curso de capacitación, para luego "migrar" a otro tipo de empleo.

Así, aún cuando exista una opinión por parte de patrones/as de "nanas peruanas" de ellas como mujeres más sumisas y dóciles, mujeres peruanas entrevistadas por Fuentes y Reyes (2003) señalan algo diferente. Para ellas, el hecho de contar con ingresos propios, el poder adquisitivo y las posibilidades de consumo que ello permite, es un argumento para criticar ciertas imágenes construidas por los chilenos sobre los peruanos como una "carga" para la sociedad, y para apelar a la necesidad de que sus derechos como trabajadoras sean respetados, al reconocimiento de sus capacidades, al respeto de sus diferencias culturales y a la integración a la sociedad.

\section{Discusión}

Las migraciones, por razones políticas o económicas, pueden producir cambios radicales en la forma como las mujeres se ven a sí mismas y se relacionan con el mundo. Como se ha señalado, aunque ciertos procesos migratorios pueden reforzar identidades de género femeninas vinculadas al ámbito reproductivo, ello suele ocurrir acompañado de efectos más cuestionadores y liberadores -muchas veces no previstos- de estereotipos y roles de género tradicionales.

Esto permite sostener que los efectos de las migraciones en las identidades de género de las mujeres son paradojales, pues el contacto con grupos culturales diferentes pueden reproducir estereotipos femeninos, y al mismo tiempo ofrecerles posibilidades de mayor autonomía y realización personal, flexibilizando comportamientos, formas de vida y de organizar la familia antes vistas como naturales; y de este modo ampliar (y complejizar) los repertorios de sentido. En la misma perspectiva, procesos migratorios motivados eminentemente por la búsqueda de recursos para la subsistencia familiar, pueden dar paso a procesos de individuación impensados.

Aunque para algunas mujeres la migración (exilio o migración económica) tiene una connotación más positiva y para otras una predominantemente negativa (castigo, desarraigo, desintegración), en la experiencia de la mayoría (y en diferentes grados) la migración parece reforzar y al mismo tiempo desafiar roles y estereotipos de género. La tensión que ello produce entre los mandatos culturales y las aspiraciones personales de mayor autonomía y desarrollo, caracterizan los procesos de aculturación psicológica de las mujeres. Esto genera un sentimiento de identidad de género "remodelado" en que, si bien áreas de significación en la vida de las mujeres siguen siendo centrales para dar sentido a sus experiencias, en cada una de ellas se han producido resignificaciones fruto del cuestionamiento de los modelos de género, las formas de hacer familia y de ser mujer. 
La incorporación de una perspectiva de género en el análisis de la experiencia de inmigrantes peruanas y exiliadas chilenas ha hecho posible visualizar y comprender este proceso. Ello demuestra la contribución que puede hacer dicha categoría en el estudio de fenómenos migratorios, evidenciando la gravitación que en ellos tienen las relaciones de género así como sus efectos en las identidades de género de mujeres y hombres.

Asumiendo que las identidades son procesos en que confluyen tanto mecanismos psicológicos como contextos sociales y culturales, cambios tan radicales en el entorno tendrán un impacto en las identidades personales. $Y$ siendo el género una dimensión fundamental en el autoconcepto, una dimensión constituyente de la identidad, dichos cambios afectarán las identidades de género de los migrantes. De este modo, los procesos de aculturación psicológica que experimentan los individuos en el contacto con grupos culturales diferentes, que ponen en juego tanto sus capacidades y motivaciones actuales como su historia, comprenden también sus identidades de género.

Múltiples son los factores que explican los efectos liberadores que pueden tener las migraciones en las identidades de género de las mujeres. La confrontación con una cultura de acogida que ofrece mayores posibilidades de autonomía personal (especialmente en el caso de las exiliadas en Europa), la falta de control social directo de las familias de origen, el sentirse como sujetos en tránsito y la autonomía económica. Sin duda existen más factores, pero lo que interesa destacar es que en estos procesos individuales (aculturación psicológica), inciden no sólo factores personales, sino también sociales, así como factores previos a la migración y otros propios de la sociedad de acogida. Ello permite sostener que para que los procesos migratorios constituyan posibilidades de enriquecimiento personal, concurren tanto características personales de las mujeres como las condiciones culturales, económicas y políticas en las cuales se realizan estas migraciones. Esto es algo que se vuelve evidente en los casos de mujeres inmigrantes y exiliadas analizados. Las diferencias entre las razones principales por las que se produce la migración (políticas o económicas), los diferentes patrones que adoptan (asociativo o autónomo), las diferencias culturales entre países europeos que acogieron a refugiados y Chile, el fuerte contraste entre las posibilidades educacionales y laborales que muchas chilenas tuvieron en el exilio y el tipo de trabajo que desempeñan peruanas en
Chile, así como los estereotipos positivos y negativos que las sociedades de acogida han construido respecto de ellas, son factores que en conjunto permiten explicar los procesos migratorios estudiados.

Pero además de los factores señalados, es necesario considerar los cambios históricos ocurridos en las dos décadas que separan ambos procesos migratorios. Entre estos cambios, la radicalización del proceso de individualización ha sido señalada como una de las transformaciones socioculturales más importantes ocurridas en las últimas décadas (Stecher, Godoy \& Díaz, 2005). La individualización alude a la posibilidad de las personas de construir de manera reflexiva y autónoma la propia identidad, o como lo señala el Programa de Naciones Unidas para el Desarrollo [PNUD] (2002) para el caso de Chile, a la ampliación y diversificación de campos de experiencia y mapas culturales que servían como modelos para la construcción de una identidad personal. A juicio de Bajoit (2003), estas transformaciones expresarían el tránsito hacia un modelo cultural identitario, en que "la plenitud personal se convierte en el valor principal, el principio último de sentido que funda la legitimidad de las conductas en todos los campos relacionales de la vida social" (p. 122).

Este proceso de individualización forma parte del contexto en el cual ocurren los actuales movimientos migratorios y permite entender muchas de sus características. Es por ello que futuras investigaciones que consideren este proceso de individualización y que incluyan una perspectiva de género, podrán ampliar nuestra comprensión de las implicancias subjetivas de las migraciones, en especial, profundizar el conocimiento de sus efectos en las identidades de género de hombres y mujeres.

\section{Referencias}

Agger, I. (1993). La pieza azul. Testimonio femenino del exilio. Santiago: Editorial Cuarto Propio.

Araujo, K., Legua, M. C. \& Ossandón, L. (2002). Migrantes andinas en Chile. El caso de la migración peruana. Santiago: Fundación Instituto de la Mujer.

Bajoit, G. (2003). Todo cambia. Santiago: LOM.

Barberá, E. (1998). Psicología del género. Barcelona: Editorial Ariel.

Berry, J. W. (1997). Inmigration, acculturation, and adaptation. Applied Psychology: An International Review, 46(1), 5-68.

BRIDGE. (2005, Octubre). Género y migración: Una mirada general. Boletín de BRIDGE, 16. Recuperado el 3 de Mayo de 2006, desde http://www.bridge.ids.ac.uk

Castles, S. \& Miller, M. J. (1998). The age of migration: International population movement in the modern world. New York: The Guilford Press. 
Córdova, N. (s/f). Mujer y migración. Recuperado el 30 Mayo de 2006, desde el sitio Web de Organización Internacional del Trabajo, Oficina Regional para América Latina y el Caribe: http://www.oit.org.pe/spanish/260ameri/ oitreg/activid/proyectos/actrav/proyectos/pdf/ ncordova.pdf

Fuentes, F. \& Reyes, N. (2003). Las que migran de Sur a Sur: Las inmigraciones intra-regionales de mujeres peruanas hacia Chile. Santiago.

Grinberg, L. \& Grinberg, R. (1996). Migración y exilio. Estudio psicoanalítico. Buenos Aires: Editorial Biblioteca Nueva.

Martínez, J. (2003). El encanto de los datos. Sociodemografía de la inmigración en Chile según el censo de 2002. Santiago: CEPAL.

Programa de Naciones Unidas para el Desarrollo. (2002). Nosotros los chilenos. Un desafío cultural. Santiago: PNUD.

Ramírez, C., García, M. \& Míguez, J. (2005). Cruzando fronteras. Remesas, género y desarrollo. Recuperado desde el sitio Web de Instituto Internacional de Investigación y Capacitación de las Naciones Unidas para la Promoción de la Mujer [INSTRAW]: http://www.un-instraw.org/en/ i mages/stories/rem mitances/documents/ cruzando_fronteras.pdf

Rebolledo, L. (2001, Invierno). Mujeres exiliadas: Con Chile en la memoria. Cyber Humanitatis, 19. Recuperado el 30 de Mayo de 2006, desde http:// www2.cyberhumanitatis.uchile.cl/19/rebolledo.html

Rebolledo, L. (2005). El impacto del exilio en la familia chilena. En T. Valdés \& X. Valdés (Eds.), Familia y vida privada. ¿Transformaciones, tensiones, resistencias y nuevos sentidos? Santiago: FLACSO, CEDEM, UNFPA.

Sassen, S. (2003). Contrageografías de la globalización.
Género y ciudadanía en los circuitos transfronterizos. Madrid: Traficantes de Sueños.

Serrano, J. (s/f). Psicología cultural. Manuscrito no publicado, Universidad de Barcelona.

Sharim, D. (2005). La identidad de género en tiempos de cambio: Una aproximación desde los relatos de vida. Psykhe, 14(2), 19-32.

Stefoni, C. (2003). Inmigración peruana en Chile. Una oportunidad a la integración. Santiago: FLACSO, Editorial Universitaria.

Stecher, A., Godoy, L. \& Díaz, X. (2005). Relaciones de producción y relaciones de género en un mundo en transformación. En L. Schvastein \& L. Leopold (Comps.), Trabajo y subjetividad. Entre lo existente y lo necesario (pp. 71-111). Buenos Aires: Paidós.

United Nations. (2002). International migration report. Recuperado el 5 de junio de 2006, desde el sitio Web de United Nations, Economic and Social Development: http:/ /www.un.org/esa/population/publications/ittmig2002/ 2002ITTMIGTEXT22-11.pdf

Vásquez, A. \& Araujo, A. M. (1990). La maldición de Ulises. Repercusiones psicológicas del exilio. Santiago: Editorial Sudamericana.

Vargas-Thils, M. (2002). Une approche biographique de la construction identitaire. Le cas de femmes péruviennes ayant migré de la campagne vers la grande ville. Thèse présentée en vue de l'obtention du grade de Docteur en Sciences Psychologiches. Université Catholique de Louvain. Louvain, France.

Wagner, H. (2004, noviembre). La influencia del "machismo" en los procesos migratorios de migrantes ecuatorianas en Madrid. Ponencia presentada a $4^{\circ}$ Congreso sobre la inmigración en España, Girona, España. 